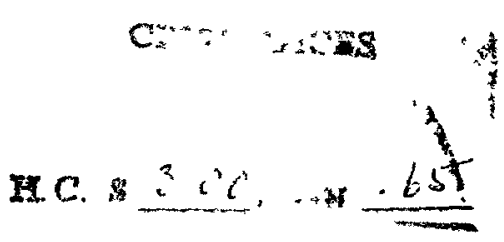

SC-TM-64-528

\title{
A METHOD FOR ESTIMATING THE DRAG COEFFICIENT OF A TUMBLING CIRCULAR CYLINDER
}

Duane E. Randall, 7421

Sandia Laboratory, Albuquerque

May 1964

\begin{abstract}
A method is presented for estimating an effective drag coefficient for a tumbling circular cylinder in hypersonic flow.
\end{abstract}

\section{LEGAL NOTICE}

This report was prepared as an account of Government sponsored work Neither the United States, nor the Commission, nor any person acting on behalf of the Commission

A Makes any warranty or representatiou, expressed or implied, with respect to the accuracy. completeness, or usefuiness of the information contained in this report, or that the we of any information, apparatus, method, or process disclosed in this report may not infringe privately ouned rights, or

B Assumes any liabilities with respect to the use of, or for damagea resulting from the use of any information, apparatus, method, or process disclosed in this report.

$A B$ used in the above. "perwon acting on behalf of the Commolssion" includes any employee or contractor of the commision, or employee of such contractor, to the axtent that such employe or contractor of the Commission, or employes of such contractor prent that disseminates, or provides access to, any information porsuant to bs employment or contract

with the Commission, or hls employment with such contractor 


\section{DISTRIBUTION:}

B. F. Murphey, 5410

G. A. Fowler, 7000

D. B. Shuster, 7400

V. E. Blake, Jr., 7410

H. E. Hansen, 7411

A. J. Clark, Jr., 7412

A. Y. Pope, 7420

H. R. Vaughn, 7421 (3)

S. McAlees, Jr. , 7421-2

D. A. Byrne, 7421-2

D. E. Randall, 7421-2

R. C. Maydew, 7422

K. F. Crowder, 7423

W. H. Curry, 7424

J. H. Scott, 7430

L. Gutierrez, 8100, Attn: A. N. Blackwell, 8118-2

C. Winter, 9130

W. F. Carstens, 3410

B. R. Allen, 3421

M. G. Randle, 3428-1, Bldg. 836

M, G. Randle, 3428-1, Bldg. 880

E. A. Paxton, Jr., 8232-2

R. C. Smelich, 3427-3(5)

\section{LE G A L N O T I CE}

This report was prepared as an account of Government sponsored work. Neither the United States, nor the Commission, nor any person acting on behalf of the Commission:

A. Makes any warranty or representation, expressed or implied, with re spect to the accuracy, completeness, or usefulness of the information contained in this report, or that the use of any information, apparatus, method, or process disclosed in this report may not infringe privately owned rights; or

B. Assumes any liabilities with respect to the use of, or for damages resulting from the use of any information, apparatus, method, or process disclosed in this report.

As used in the above, "person acting on behalf of the Commission" includes any employee or contractor of the Commission, or employee of such contractor, to the extent that such employee or contractor of the Commission, or employee of such contractor prepares, disseminates, or provides access to, any information pursuant to his employment or contract with the Commission, or his employment with such contractor. 


\section{DISCLAIMER}

This report was prepared as an account of work sponsored by an agency of the United States Government. Neither the United States Government nor any agency Thereof, nor any of their employees, makes any warranty, express or implied, or assumes any legal liability or responsibility for the accuracy, completeness, or usefulness of any information, apparatus, product, or process disclosed, or represents that its use would not infringe privately owned rights. Reference herein to any specific commercial product, process, or service by trade name, trademark, manufacturer, or otherwise does not necessarily constitute or imply its endorsement, recommendation, or favoring by the United States Government or any agency thereof. The views and opinions of authors expressed herein do not necessarily state or reflect those of the United States Government or any agency thereof. 


\section{DISCLAIMER}

Portions of this document may be illegible in electronic image products. Images are produced from the best available original document. 
TABLE OF CONTENTS

NOMFNCLATURE

SUMMARY

Introduction

Theoretical Development

Results

LIST OF REFERENCES
Page

4

5

7

7

11

13 
$A_{R}$ Reference area for drag coefficient, $\mathrm{ft}^{2}$

$A_{S}$ Surface area of body, $\mathrm{ft}^{2}$

$C_{P}$ Pressure coefficient, $\frac{P-P_{\infty}}{q_{\infty}}$

$C_{D}$ Drag coefficient, $\frac{D}{q_{\infty} A_{R}}$

D Drag force, lbs

K Density ratio across a normal shock, $\frac{\rho_{1}}{\rho_{2}}$

$L \quad$ Length, $\mathrm{ft}$

$P \quad$ Pressure, $\mathrm{lbs} / \mathrm{ft}^{2}$

q Dynamic pressure, $\frac{1}{2} \rho \mathrm{V}^{2}, \mathrm{lbs} / \mathrm{ft}^{2}$

$r$ Local radius, $\mathrm{ft}$

R Radius of cylinder, $\mathrm{ft}$

V Velocity, $\mathrm{ft} / \mathrm{sec}$

a Angle of attack, radians

$\theta \quad$ Angle between normal to surface and free stream, radians

$\rho \quad$ Density, slugs $/ \mathrm{ft}^{3}$

\section{Subscripts}

$\infty \quad$ Free stream

- Stagnation

1 Upstream of normal shock

2 Downstream of normal shock

a Axial flow; i. e. , cylinder axis parallel to free-stream velocity vector

c Crossflow; i. e., cylinder axis normal to free-stream velocity vector

$\alpha \quad$ For an angle of attack other than zero

$\vec{\alpha} \quad$ Mean value averaged over an angle-of-attack range from 0 to $2 \pi$ 


\section{SUMMARY}

Safety analyses performed on Systems for Nuclear Auxiliary Power (SNAP) require a knowledge of the trajectory and aerodynamic heating experienced by reactor components subsequent to reactor disassembly and separation. For the reactor-type power supplies, fuel rods constitute one of the most critical components in this respect. Presented herein is a method for estimating the effective drag coefficient for circular cylinders in hypersonic now. 



\title{
A METHOD FOR ESTIMATING THE DRAG COEFFICIENT \\ OF A TUMBLING CIRCULAR CYLINDER
}

\author{
Introduction
}

Early proposals on nuclear auxiliary power supplies for space application employ design concepts which result in disassembly and separation of the reactor components during re-entry. Safety analyses, then, require that the trajectory and re-entry heating experienced by these various components be determined. This requires some knowledge of the drag characteristics of the component under consideration.

Among the most critical elements to be considered are reactor fuel elements. Cylindrical circular rods with length-to-diameter ratios in the range of 10 to $40^{1} *$ appear to be typical of the fuel elements for the early reactor-type power supplies. Since fuel-element exposure and separation are left to the vagaries of reactor burnup and vehicle dynamics, it is considered very likely that the fuel rods will experience some sort of random tumbling motion, at least during a significant part of their trajectory, subsequent to separation from the parent vehicle. This paper presents a method for estimating an effective drag coefficient for a tumbling cylindrical rod in hypersonic flow.

\section{Theoretical Development}

According to the modified Newtonian theory, the pressure distribution on a body is given by

$$
C_{P}=C_{P \max } \cos ^{2} \theta
$$

where $\theta$ is the angle between a normal to the body surface and the free-stream direction. Then the local pressure is given by

$$
P=P_{\infty}+\left(P_{02}-P_{\infty}\right) \cos ^{2} \theta
$$

The continuity and momentum equations for flow through a normal shock are, respectively:

$$
\rho_{1} v_{1}=\rho_{2} v_{2}
$$

and

$$
P_{1}+\rho_{1} v_{1}^{2}=P_{2}+\rho_{2} v_{2}^{2}
$$

* Superscripts refer to references at the end of this report. 
In the stagnation region downstream of a normal shock, incompressible flow relations approximate the real flow situation.

Therefore:

$$
\mathrm{P}_{\mathrm{o} 2}=\mathrm{P}_{2}+\frac{1}{2} \rho_{2} \mathrm{~V}_{2}^{2}
$$

Combining (5) with (3) and (4) gives

$$
P_{o 2}=P_{\infty}+2 q_{\infty}\left[1-\frac{1}{2} \frac{\rho_{1}}{\rho_{2}}\right] \text {. }
$$

Substituting this expression in (2) gives

$$
P=P_{\infty}+2 q_{\infty}\left[1-\frac{1}{2} \frac{\rho_{1}}{\rho_{2}}\right] \cos ^{2} \theta
$$

The drag of a body in Newtonian flow is

$$
D=\int P \cos \theta d A_{S}
$$

where the integration is carried out over the surface area of the body which is exposed to the free stream. That part of the body surface which is in shadow regions; $i$. e., not exposed to the freestream velocity vector, is considered to have zero pressure.

Then substituting for the pressure from (7) and expressing as a drag coefficient:

$$
C_{D}=\frac{P_{\infty}}{q_{\infty} A_{R}} \int \cos \theta d A_{S}+\frac{2-\frac{\rho_{1}}{\rho_{2}}}{A_{R}} \int \cos ^{3} \theta d A_{S}
$$

Consider a circular cylinder of radius, $R$, and length, $L$, broadside to the flow

$$
\mathbf{d A}_{\mathbf{S}}=\mathbf{L} \mathbf{R d} \theta
$$

For this case, let the projected frontal area, $L D$, be the reference area, and let $K$ represent the density ratio across a normal shock. Then

$$
C_{D_{c}}=\frac{P_{\infty}}{q_{\infty} L D} \int_{\frac{-\pi}{2}}^{\frac{\pi}{2}} \cos \theta L R d \theta+\frac{2-K}{L D} \int_{\frac{-\pi}{2}}^{\frac{\pi}{2}} \cos ^{3} \theta L R d \theta
$$

Carrying out the integration, results in

$$
C_{D_{c}}=\frac{P_{\infty}}{q_{\infty}}+\frac{2}{3}(2-K)
$$


Consider the same cylinder aligned axially with the flow

$$
d A_{s}=2 \pi r d r
$$

According to the Newtonian theory, a uniform pressure equal to stagnation pressure $\left(P_{\mathrm{O}_{2}}\right)$ would exist over the face of the cylinder. Actually, from the stagnation point, the flow expands radially around the edge of the face. Stoney ${ }^{2}$ has measured the pressure distribution over this geometry and found a pressure variation with radius such that $P / P_{O_{2}}=f(r / R)$ where

$$
P / P_{o_{2}}=1.0 @ r / R=0
$$

and

$$
P / P_{o_{2}} \cong 0.53 @ r / R=1.0
$$

Integrating Stoney's curve results in a mean pressure acting over the face of the cylinder equal to 90. 9 percent of the stagnation pressure. Assuming a uniform pressure distribution equal to this magnitude results in, from (8)

$$
D=\int_{0}^{R} 0.909 P_{o_{2}} \cos \theta 2 \pi r d r
$$

Integrating and substituting for $\mathrm{P}_{\mathrm{O}_{2}}$ from (6)

$$
C_{D_{a}}=0.909\left[\frac{P_{\infty}}{q_{\infty}}+(2-K)\right]
$$

where the reference area $\pi R^{2}$ has been used.

To convert the above value to the same reference area as the case for the cylinder broadside

$$
\begin{aligned}
& \left(A_{r}=L D\right) \\
& C_{D_{a}}=0.909\left[\frac{P_{\infty}}{q_{\infty}}+(2-K)\right] \frac{\pi}{4} \frac{D}{L}
\end{aligned}
$$

Now consider the case of the cylinder tumbling after separation from the parent vehicle. The angular velocity due to the tumbling motion is considered to be negligibly small in relation to the re-entry velocity. Then the case of a cylinder tumbling in a plane perpendicular to the trajectory path; i. e., flat spin, is represented by the case of flow broadside to the cylinder. For the other extreme, the cylinder tumbling end-over-end in the plane of the trajectory, the angle-average drag 
coeflicient would be determined from

$$
C_{D_{\bar{\alpha}}}=\frac{4 \int_{\mathrm{O}}^{\frac{\pi}{2}} \mathrm{C}_{\mathrm{D}_{\alpha} \mathrm{d} \alpha}}{4 \int_{\mathrm{O}}^{\frac{\pi}{2}} \mathrm{~d} \alpha}=\frac{2}{\pi} \int_{0}^{\frac{\pi}{2}} \mathrm{C}_{\alpha} \mathrm{d} \alpha
$$

This assumes a constant angular velocity throughout one revolution. Under the conditions of interest here, this is not considered a severe restriction.

For a cylinder at angle of attark we assume the total drag force to be composed of axial and crossflow components.

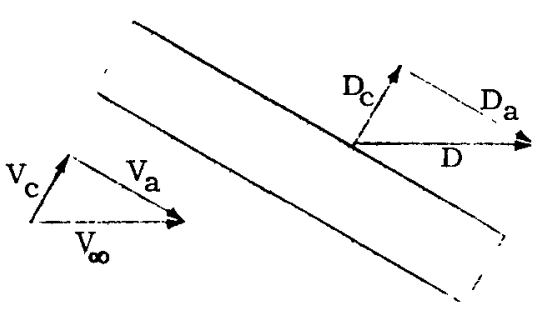

then $\quad \mathrm{D}=\mathrm{D}_{\mathrm{c}} \sin \alpha+\mathrm{D}_{\mathrm{a}} \cos \alpha$

or $\quad C_{D_{\alpha}} q_{\infty} A_{R}=C_{D_{c}} q_{c} A_{R} \sin \alpha+C_{D_{a}} q_{a} A_{R} \cos \alpha$

Also

$$
\begin{aligned}
& \mathrm{q}_{c}=\frac{1}{2} \rho_{\infty} \mathrm{v}_{\mathrm{c}}^{2}=\frac{1}{2} \rho_{\infty} \mathrm{v}_{\infty}^{2} \sin ^{2} \alpha=\mathrm{q}_{\infty} \sin ^{2} \alpha \\
& \mathrm{q}_{\mathrm{a}}=\frac{1}{2} \rho_{\infty} \mathrm{v}_{\mathrm{a}}^{2}=\frac{1}{2} \rho_{\infty} \mathrm{v}_{\infty}^{2} \cos ^{2} \alpha=\mathrm{q}_{\infty} \cos ^{2} \alpha
\end{aligned}
$$

Then

$$
C_{D_{\alpha}}=C_{D_{C}} \sin ^{3} \alpha+C_{D_{a}} \cos ^{3} \alpha
$$

or from previous results

$$
C_{D_{\alpha}}=\left[\frac{P_{\infty}}{q_{\infty}}+\frac{2}{3}\left(2-K_{c}\right)\right] \sin ^{3} \alpha+0.909 \frac{\pi D}{4 L}\left[\frac{P_{\infty}}{q_{\infty}}+\left(2-K_{a}\right)\right] \cos ^{3} \alpha
$$

Now

$$
\begin{aligned}
& K_{c}=f\left(M_{\infty} \sin \alpha\right) \\
& K_{a}=f\left(M_{\infty} \cos \alpha\right)
\end{aligned}
$$


This fact introduces some difficulty in integrating (19). The simplest expedient to circumvent this difficulty would be to assume

$$
K_{c}=K_{a}=K=f\left(M_{\infty}\right)
$$

The effect of this assumption has been calculated for the particular case of a perfect gas and

$$
\mathbf{M}=10
$$

The calculations show that employing this assumption results in overestimating the value of $\mathrm{C}_{\mathrm{D}_{\alpha}}$ by a maximum of slightly greater than 1 percent at a particular value of $\alpha$ with a lesser error at other angles. Upon integrating over one revolution, the error in $\mathbf{C}_{D}$ would be much less than this maximum value. At other conditions of interest; real gas and $M>10$, the error would be less than that for the case calculated here. Then substituting (19) into (14) and integrating

$$
C_{D_{\alpha}}=\frac{4}{3 \pi}\left[\frac{P_{\infty}}{q_{\infty}}+\frac{2}{3}(2-K)\right]+0.303 \frac{D}{L}\left[\frac{P_{\infty}}{q_{\infty}}+(2-K)\right]
$$

Over the flight regime of interest; $M \geq 10$ and altitudes from 70,000 feet to 250,000 feet, the $\frac{P_{\infty}}{q_{\infty}}$ term amounts to 1.2 percent or less of the $2 / 3(2-K)$ term. Neglecting the $\frac{P_{\infty}}{q_{\infty}}$ term then permits simplifying (20) to the following result

$$
C_{D_{\bar{\alpha}}}=(2-K)\left[0.283+\frac{0.303}{L / D}\right]
$$

\section{Results}

Figure 1 shows values calculated for a circular cylinder of $L / D=10$ in the various flow configurations discussed above. The calculations have been carried out, using both perfect gas tables 3 and real gas (in thermodynamic equilibrium) tables ${ }^{4}$. As is expected, the drag coefficients are essentially independent of Mach number in the hypersonic flow regime. Included in the figure are some experimental data from Hoerner ${ }^{5}$ which shows good agreement with the calculated values. The figure shows that for a circular cylinder of $L / D=10$ tumbling end-over-end in the plane of the trajectory, the effective drag coefficient is approximately $=0.6$ in hypersonic flow. 


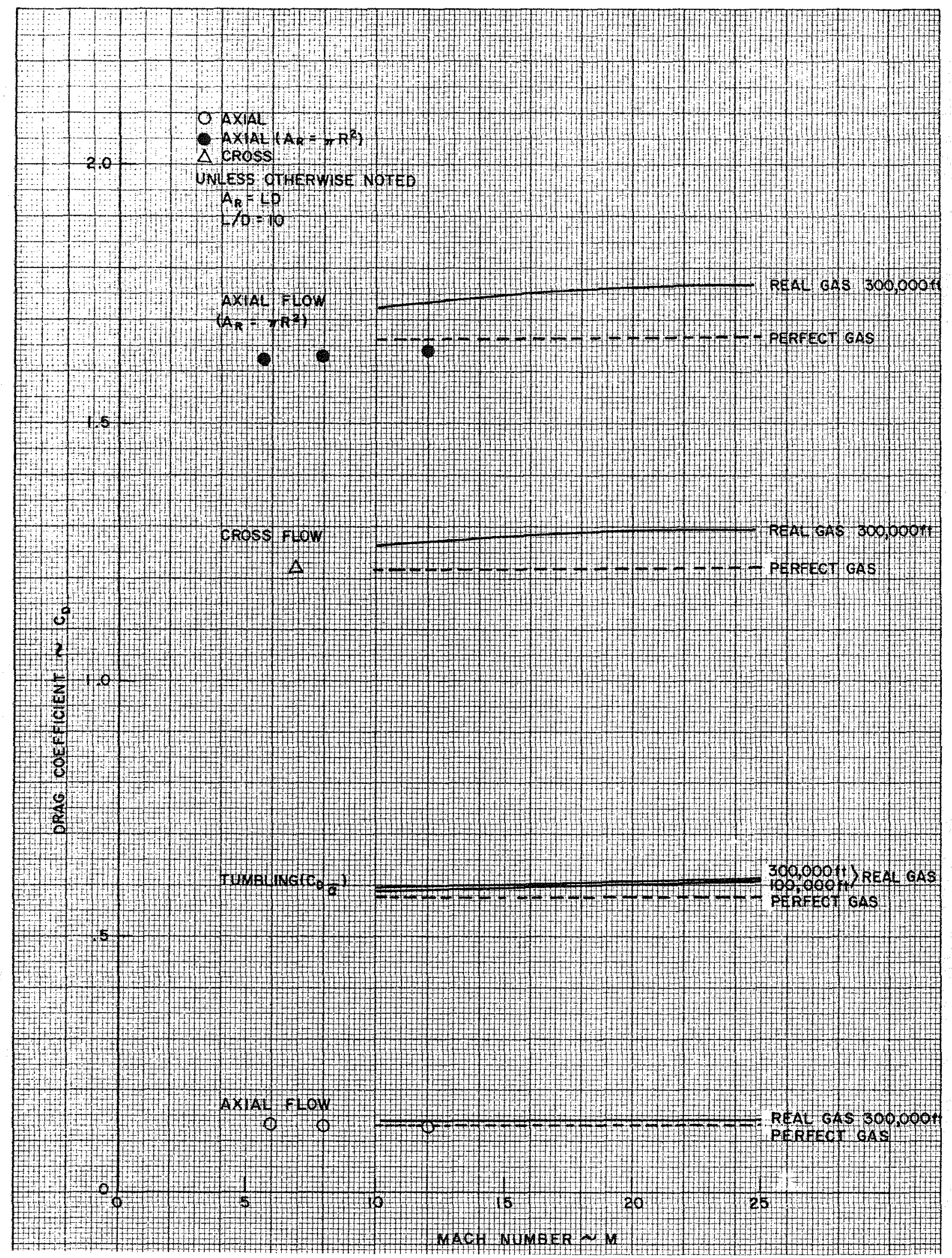

Figure 1. Drag Coefficients of Circular Cylinders 


\section{LIST OF REFERENCES}

1. Becherer, C. B. and Clark, A. J., Jr. , Summary Report of Aerospace Nuclear Systems (U), SCTM 96-63(71), July 1963, SECRET RD.

2. Stoney, W. E. Jr., and Swanson, A. G. , Heat Transfer Measured on a Flat-Face Cylinder in Free Flight at Mach Numbers up to 13.9, NACA RM-L57E13, June 17, 1957.

3. Ames Research Staff; Equations. Tables and Charts for Compressible Flow, NACA Report 1135, 1953.

4. Wittliff, C. E. and Curtis, J. T., Normal Shock Wave Parameters in Equilibrium Air, CAL-111, November 1961.

5. Hoerner, S. F. . Fluid-Dynamic Drag, 1958. 